\title{
Efeito hipolipemiante da suplementação dietética com a farinha do cubiu (Solanum sessiliflorum Dunal) em ratos hipercolesterolêmicos
}

\begin{abstract}
MAIA, J.R.P.; SCHWERTZ, M.C.2; SOUSA, R.F.S. ${ }^{3}$; AGUIAR, J.P.L.4; LIMA, E.S..$^{*}$. ${ }^{1}$ Nutricionista, mestranda em Ciência de Alimentos pela Universidade Federal do Amazonas-UFAM. ${ }^{2}$ Nutricionista, mestranda em Ciência de Alimentos pela Universidade Federal do Amazonas-UFAM. ${ }^{3 Z o o t e c n i s t a ~ d o ~ I n s t i t u t o ~}$ Nacional de Pesquisas da Amazônia (INPA). ${ }^{4}$ Especialista em Nutrição e Ciência de Alimentos, pesquisador do Instituto Nacional de Pesquisas da Amazônia (INPA). ${ }^{5}$ Farmacêutico, doutor em Farmácia, professor adjunto da Faculdade de Ciências Farmacêuticas da UFAM e Coordenador do Programa de Pós-graduação (Mestrado) em Ciências Farmacêuticas na UFAM. *E.S.LIMA. E-mail: eslima@ufam.edu.br, fone/fax: (92) 3305.5000.
\end{abstract}

\begin{abstract}
RESUMO: Estudos com frutas e vegetais ricos em fibra alimentar tem demonstrado efeito redutor das concentrações sanguíneas de colesterol total, atuando de forma preventiva contra a hipercolesterolemia. O objetivo do presente trabalho foi analisar a composição química da farinha de cubiu e avaliar o efeito de seu consumo sobre a lipemia de ratos hipercolesterolêmicos. Foram utilizados 8 animais para cada tratamento, em 7 grupos sendo: 1 controle; 3 experimentais com $5 \%, 25 \%$ e $50 \%$ da recomendação de fibras (AIN-93) provenientes da farinha de cubiu; e 3 grupos per feeding tendo celulose e pectina como fonte de fibra alimentar nas mesmas proporções dos grupos experimentais. Ao final do ensaio foi verificado que não houve variação significativa no consumo de ração pelos animais e no ganho de massa corporal no decorrer do experimento. Os tratamentos com farinha de cubiu reduziram as concentrações de colesterol total $(-21,6 \%)$, LDL-c (-56,8\%), aumentaram a excreção de colesterol fecal $(+116 \%)$, e diminuíram o colesterol hepático $(-32,1 \%)$. Nenhum dos tratamentos promoveu alteração significativa nas concentrações de triglicerídeos. Os tratamentos com pectina e celulose demonstraram resultados semelhantes aos do cubiu. Os resultados observados servem como base para futuros estudos visando o aproveitamento biotecnológico deste fruto.
\end{abstract}

Palavras-chave: Solanum sessiliflorum Dunal, cubiu, fibra alimentar, hipercolesterolemia.

ABSTRACT: Hypolipidemic effect of diet supplementation with cocona (Solanum sessiliflorum Dunal) flour in hypercholesterolemic rats. Studies with fruit and vegetables rich in dietary fiber have shown lowering effects on the blood concentrations of total cholesterol (TC), acting preventively against hypercholesterolemia. The aim of this study was to analyze the chemical composition of cocona and evaluate the effect of the consumption of cocona flour on lipemia of Wistar rats with hypercholesterolemia. Eight animals were used for each treatment, in 7 groups: control; 3 experimental groups with $5 \%, 25 \%$ and $50 \%$ of the recommended fiber (AIN-93) from cocona flour; 3 groups per feeding with pectin and cellulose as source of dietary fiber, in the same proportions of the experimental groups. At the end of the assay, we verified that there were not significant variations in the consumption of the animals and the body weight during the experiment. Treatments with cocna flour were responsible for reducing the concentrations of total cholesterol $(-21.6 \%)$, LDL-c $(-56.8 \%)$, increasing the excretion of fecal cholesterol $(+116 \%)$ and lowering the liver cholesterol $(-32.1 \%)$. None of the treatments significantly altered the triglyceride concentrations. Treatments using pectin and cellulose show results similar to cocona. The observed results can be used in further studies aimed at the biotechnological exploitation of this fruit.

Key words: Solanum sessiliflorum Dunal, cocona, dietary fiber, hypercholesterolemia.

Rev. Bras. PI. Med., Campinas, v.17, n.1, p.112-119, 2015. 


\section{INTRODUÇÃO}

A hipercolesterolemia é responsável pela maioria das mortes precoces em adultos e está associada a doenças cardiovasculares (DCV), principalmente o acidente vascular cerebral e a doença arterial coronariana (Toshima et al., 2000). O estilo de vida moderno onde se tem a diminuição da prática de atividade física, ingestão aumentada de alimentos ricos em colesterol e gorduras e o baixo consumo de vegetais fontes de antioxidantes e fibras, contribuem para o aparecimento da hipercolesterolemia e consequentemente para o surgimento das DCV. Tratamentos com drogas hipocolesterolemiantes tem demonstrado efeito regulatório das concentrações de colesterol, no entanto nem todos os pacientes toleram este tipo de tratamento. Em alguns casos esses medicamentos podem causar efeitos colaterais e também elevar os custos com a saúde (Bhatnagar, 1998; Ward et al., 2007). Estudos epidemiológicos revelaram que o consumo de frutas e hortaliças é responsável por importantes efeitos na redução das concentrações de colesterol sanguíneo e também na redução da absorção intestinal de lipídeos, devido a esses alimentos serem fontes de fibras (Hu et al., 2000; Fung et al, 2001). Contudo, poucas pesquisas foram realizadas com frutos amazônicos para verificar seus possíveis efeitos sobre os níveis lipídicos.

Dentre os frutos nativos da Amazônia, o cubiu (Solanum sessiliflorum Dunal) se destaca por conter expressivo teor de fibra alimentar (Pahlen, 1977), apresenta possibilidades múltiplas de uso, fácil cultivo e elevada produtividade (Silva Filho, 1998). Seus frutos podem ser consumidos in natura ou na forma de geléias, néctar, doces, compotas e tempero de sopas de peixe. Popularmente o cubiu é utilizado para redução dos níveis de colesterol e de ácido úrico (Silva Filho et al., 1997), porém é importante validar cientificamente sua ação hipocolesterolêmica, uma vez que seu efeito hipoglicemiante já foi comprovado em estudo tendo ratos como modelo experimental (Yuyama et al., 2005). Portanto, o presente estudo teve como objetivo avaliar o efeito da farinha de cubiu (Solanum sessiliflorum Dunal) sobre a lipemia de ratos hipercolesterolêmicos.

\section{MATERIAIS E MÉTODOS}

\section{Obtenção da farinha de cubiu}

Foram utilizados frutos da mesma etnovariedade, coletados em estágio de amadurecimento comercial, oriundos da Estação Experimental do Ariau, do Instituto Nacional de Pesquisas da Amazônia (INPA). Os mesmos foram transportados em caixas de isopor até o Laboratório de Alimentos e Nutrição do INPA onde foram selecionados apenas frutos saudáveis, adequados ao processamento. Posteriormente, os frutos foram lavados em água corrente, retirados os pedúnculos, sementes e a placenta. Após a lavagem, os frutos foram sanitizados com solução de hipoclorito à $200 \mathrm{ppm}$ por 30 minutos, enxaguados em água corrente, seguido do branqueamento térmico, à temperatura de $90^{\circ} \mathrm{C}$ por 3 minutos e choque térmico em banho de gelo. Na sequência, os frutos foram colocados em estufa com circulação de ar forçada a $60^{\circ} \mathrm{C}$ até peso constante. Os frutos secos foram liquidificados, homogenizados e acondicionados em sacos de polietileno de $2 \mathrm{~kg}$ e congelados a temperatura de $-15^{\circ} \mathrm{C}$ até o momento de sua utilização. Uma alíquota em triplicata foi retirada, para fins de análises química.

\section{Análise química do cubiu}

Os teores de umidade, proteína, lipídeos e cinza foram determinados de acordo com a metodologia descrita pela AOAC (1995). A fração fibra alimentar foi quantificada pelo método enzímicograviométrico proposto por Asp et al. (1983). Neste ensaio utilizaram-se as enzimas TERMAMYL 120L (a-amilase), com atividade declarada de $120 \mathrm{KNU} / \mathrm{g}$; ALCALASE 0.6L (protease), com atividade declarada de 0.6AU/g; e AMG 200 (amiloglicosidase) com atividade declarada de $200 \mathrm{AGU} / \mathrm{ml}$, todas fabricadas pela Novozymes Ltda. e mantidas em refrigerador (temperatura média de $5^{\circ} \mathrm{C}$ ) após cada uso. A atividade das enzimas foi testada periodicamente, utilizando o kit Sigma TDF-C10a. O teor de carboidratos foi calculado por diferença.

\section{Ensaio biológico}

As dietas foram preparadas de acordo com o American Society for Nutrition AIN- 93 (Reeves et al., 1993), modificadas pela substituição de 3,5\% de óleo de soja por banha de porco (obtida no mercado local), como fonte de gordura saturada e para potencializar seu efeito hipercolesterolêmico foram acrescentados $1 \%$ de colesterol (C8503, Sigma, Alemanha) e 0,1\% de ácido cólico (C1129, Sigma, Alemanha) às dietas. Nas dietas experimentais, $5 \%$, $25 \%$ e $50 \%$ do total de fibra alimentar recomendada pela AIN-93 (12) foi proveniente da farinha de cubiu. As dietas dos grupos per feeding foram formuladas tendo como fonte de fibra alimentar pectina (Vetec, Brasil) e celulose (Rhoster, Brasil), nas mesmas proporções dos grupos experimentais. Todas as dietas receberam $20 \%$ de caseína comercial a qual contem aproximadamente $92 \%$ de proteína. (Tabela 1).

O ensaio biológico foi realizado conforme os princípios éticos da experimentação animal descritos 
TABELA 1. Composição das dietas (g/100 g de dieta).

\begin{tabular}{|c|c|c|c|c|c|c|c|}
\hline \multirow[t]{2}{*}{ Ingredientes } & \multicolumn{7}{|c|}{ Dietas/Grupos } \\
\hline & Controle & $\begin{array}{c}5 \% \text { farinha } \\
\text { de cubiu }\end{array}$ & $\begin{array}{c}25 \% \text { farinha } \\
\text { de cubiu }\end{array}$ & $\begin{array}{c}50 \% \text { farinha } \\
\text { de cubiu }\end{array}$ & $\begin{array}{l}5 \% \text { pectina } \\
\text { e celulose }\end{array}$ & $\begin{array}{c}25 \% \\
\text { pectina } \\
\text { e celulose }\end{array}$ & $\begin{array}{c}50 \% \\
\text { pectina } \\
\text { e celulose }\end{array}$ \\
\hline Caseína & 20 & 20 & 20 & 20 & 20 & 20 & 20 \\
\hline Sacarose & 10 & 10 & 10 & 10 & 10 & 10 & 10 \\
\hline Óleo de soja & 3,5 & 3,5 & 3,5 & 3,5 & 3,5 & 3,5 & 3,5 \\
\hline Banha de porco & 3,5 & 3,5 & 3,5 & 3,5 & 3,5 & 3,5 & 3,5 \\
\hline Colesterol & 1 & 1 & 1 & 1 & 1 & 1 & 1 \\
\hline Ácido Cólico & 0,1 & 0,1 & 0,1 & 0,1 & 0,1 & 0,1 & 0,1 \\
\hline Celulose & 5 & 4,75 & 3,75 & 2,5 & 4,92 & 4,58 & 4,17 \\
\hline Pectina & - & - & - & - & 0,083 & 0,417 & 0,833 \\
\hline Farinha de cubiu & - & 0,64 & 3,21 & 6,41 & - & - & - \\
\hline Mix de Minerais & 3,5 & 3,5 & 3,5 & 3,5 & 3,5 & 3,5 & 3,5 \\
\hline Mix Vitamínico & 1 & 1 & 1 & 1 & 1 & 1 & 1 \\
\hline L-cistina & 0,3 & 0,3 & 0,3 & 0,3 & 0,3 & 0,3 & 0,3 \\
\hline Bitartarato de colina & 0,25 & 0,25 & 0,25 & 0,25 & 0,25 & 0,25 & 0,25 \\
\hline Amido & & & Para & ompletar $100 \mathrm{~g}$ & & & \\
\hline
\end{tabular}

na Lei $n^{\circ} 11.794$ de 2008 (Brasil, 2008), aprovado pelo comitê de ética em pesquisas animais da Universidade Federal do Amazonas, sob o protocolo 004/2010-CEEA.

Foram utilizados ratos machos, adultos, da linhagem Wistar (Rattus novergicus), pesando aproximadamente $180 \mathrm{~g}$, provenientes do Biotério Central do INPA. Durante todo o experimento os animais foram mantidos em ambiente com temperatura controlada de 26 $\pm 2{ }^{\circ} \mathrm{C}$ e ciclo claro-escuro de 12 horas. 0 período experimental foi dividido em 2 fases: fase de indução da hipercolesterolemia, onde foram utilizados 80 animais que receberam, durante 21 dias, dieta hipercolesterolêmica e água ad libitum; e fase de tratamentos e monitoração das variáveis, onde foram selecionados 56 animais hipercolesterolêmicos divididos aleatoriamente em 7 grupos: controle (dieta hipercolesterolêmica), 5\%, 25\% e 50\% da recomendação de fibra alimentar da AIN-93 proveniente da farinha de cubiu e 3 grupos per feeding, com as mesmas concentrações de fibras - solúvel (pectina) e insolúvel (celulose) - dos grupos experimentais, $5 \%, 25 \%$ e $50 \%$.

A massa corporal, ingestão e excreção fecal foram mensuradas durante todo o período do ensaio. A ingestão alimentar e excreção fecal foram controladas diariamente, enquanto que a massa corporal, semanalmente. No primeiro dia da etapa de tratamento (Dia 1) e ao final do experimento (Dia 14), foram coletadas amostras de sangue via punção cardíaca de todos os animais, previamente anestesiados e analgesiados com cloridrato de cetamina $(1,5 \mathrm{ml} / \mathrm{Kg}$ massa corporal; Syntec, São
Paulo-Brasil) e cloridrato de xylazina $(0,15 \mathrm{ml} / \mathrm{Kg}$ massa corporal; E.H.G. Agroframa; São PauloBrasil). Após a última coleta de sangue, procedeu-se a eutanásia em todos os animais para rapidamente realizar-se a coleta dos fígados.

Para determinação das concentrações de colesterol total (CT), lipoproteína de alta densidade (HDL-c) e triglicerídeos (TG) plasmáticos foram utilizados kit enzimáticos da Labtest Diagnóstica S.A (Minas Gerais-Brasil) e o analisador bioquímico automatizado Cobas Mira Plus (Roche, Alemanha). A lipoproteína de baixa densidade (LDL-C) foi calculada a partir da equação Friedewald et al. (1972). As concentrações de colesterol fecal e hepático foram determinadas a partir da metodologia de Haug \& HostmarK (1987), utilizando-se kit enzimático da Labtest Diagnóstica S.A. (Brasil).

\section{Análise estatística}

Para análise estatística foi realizado primeiramente o teste da normalidade de ShapiroWilk. Em seguida para dados normais procedeuse o teste ANOVA e para os demais o teste não paramétrico de Kruskal-Wallis. A análise estatística foi realizada com auxílio do programa $\mathrm{R}$, considerando um nível de significância de 5\% $(p<0,05)$.

\section{RESULTADOS}

Conforme os dados apresentados na Tabela 2 , verifica-se que a amostra de cubiu analisada possui alto teor de umidade, baixa concentração de proteínas e lipídeos, e ainda considerado teor

Rev. Bras. PI. Med., Campinas, v.17, n.1, p.112-119, 2015. 
de fibra alimentar, sendo a fração predominante a insolúvel com $66,6 \%$.

TABELA 2. Composição química do cubiu em matéria fresca e da farinha

\begin{tabular}{lcc}
\hline Parâmetro & Fruto Fresco & Farinha \\
\hline Fibra solúvel (\%) & $1,3 \pm 0,00$ & $13,30 \pm 0,00$ \\
Fibra insolúvel (\%) & $2,6 \pm 0,00$ & $25,94 \pm 0,00$ \\
Umidade (\%) & $90,18 \pm 0,44$ & $8,22 \pm 0,27$ \\
Lipídeos (\%) & $0,31 \pm 0,00$ & $1,49 \pm 0,00$ \\
Proteína & $0,57 \pm 0,01$ & $6,99 \pm 0,00$ \\
Cinzas (\%) & $0,45 \pm 0,02$ & $6,75 \pm 0,00$ \\
Carboidrato (\%) & $8,49 \pm 0,02$ & $76,55 \pm 0,2$ \\
\hline
\end{tabular}

*Valores foram expressos como média \pm desvio padrão.

Os valores médios verificados após a avaliação do consumo alimentar e do ganho de massa corporal dos animais, não demonstrou diferença significativa $(p>0,05)$ entre os grupos.

A tabela 3 demonstra a concentração média de CT, HDL-C, LDL-c e TG no plasma dos animais, no primeiro dia (Dia 1) e no $14^{\circ}$ dia (Dia 14) de tratamento com as dietas experimentais. A oferta de dieta acrescida de colesterol, ácido cólico e banha de porco por 21 dias resultou em hipercolesterolemia nos animais, evidenciada pelas altas concentrações de CT, que se apresentam cerca de 96,9\% maior do que a descrita pela literatura como concentração normal ( $\pm 64,1 \mathrm{mg} / \mathrm{dl}$ ) (Moundras et al., 1997). Sendo assim, pode-se afirmar que o método de indução utilizado foi eficaz.

Não foram verificadas variações significativas nas concentrações de TG entre os grupos experimentais e o grupo controle $(p>0,05)$ (Tabela 3). Nos grupos dos animais que receberam tratamento com $50 \%$ de farinha de cubiu e $25 \%$ de pectina e celulose, foram observadas elevações das concentrações de TG sanguíneos. Nos animais que receberam os demais tratamentos, inclusive o controle, houve redução dessas concentrações. 0 grupo que recebeu dieta com $25 \%$ de farinha de cubiu apresentou a maior redução, em torno de $18,9 \%$.

Após 14 dias de tratamento (Dia 14)

TABELA 3. Colesterol total, triglicerídeos, HDL-c e LDL-c de ratos submetidos a dieta hipercolesterolêmica e tratados com farinha de cubiu.

\begin{tabular}{|c|c|c|c|c|c|c|c|c|}
\hline \multirow[t]{2}{*}{ Grupos } & \multicolumn{2}{|c|}{ Colesterol total $(\mathrm{mg} / \mathrm{dL})^{*}$} & \multicolumn{2}{|c|}{ Triglicerídeos $(\mathrm{mg} / \mathrm{dL})^{*}$} & \multicolumn{2}{|c|}{$\begin{array}{c}\text { HDL-c } \\
(\mathrm{mg} / \mathrm{dL})^{*}\end{array}$} & \multicolumn{2}{|c|}{$\begin{array}{c}\text { LDL-C } \\
(\mathrm{mg} / \mathrm{dL})^{*}\end{array}$} \\
\hline & Dia 1 & Dia 14 & Dia 1 & Dia 14 & Dia 1 & Dia 14 & Dia 1 & Dia 14 \\
\hline Controle & $133 \pm 31^{\text {a }}$ & $187 \pm 23^{a}$ & $95 \pm 13^{a}$ & $84 \pm 18^{a}$ & $38 \pm 4$ & $32 \pm 2 b$ & $75 \pm 28^{a}$ & $138 \pm 22^{a}$ \\
\hline \multicolumn{9}{|l|}{$5 \%$ farinha } \\
\hline de cubiu & $131 \pm 35^{a}$ & $111 \pm 16^{b}$ & $71 \pm 16^{a}$ & $64 \pm 42^{\text {a }}$ & $40 \pm 3 \mathrm{bc}$ & $55 \pm 6^{a}$ & $76 \pm 34$ & $43 \pm 19$ \\
\hline \multicolumn{9}{|l|}{$25 \%$ farinha } \\
\hline de cubiu & $131 \pm 41^{a}$ & $107 \pm 41 b$ & $67 \pm 13^{a}$ & $55 \pm 26$ a & $45 \pm 7$ ab & $53 \pm 5^{a}$ & $72 \pm 37$ a & $42 \pm 39$ b \\
\hline \multicolumn{9}{|l|}{$50 \%$ farinha } \\
\hline de cubiu & $131 \pm 32^{a}$ & $102 \pm 8^{b}$ & $79 \pm 25^{a}$ & $82 \pm 27$ a & $50 \pm 7$ a & $58 \pm 6^{a}$ & $64 \pm 31$ a & $27 \pm 10^{b}$ \\
\hline \multicolumn{9}{|l|}{$5 \%$ pectina } \\
\hline e celulose & $130 \pm 32^{a}$ & $100 \pm 11 b$ & $81 \pm 28^{a}$ & $72 \pm 27$ a & $49 \pm 7$ a & $55 \pm 9$ a & $64 \pm 33^{a}$ & $31 \pm 12^{b}$ \\
\hline \multicolumn{9}{|l|}{$25 \%$ pectina } \\
\hline e celulose & $118 \pm 25^{a}$ & $113 \pm 17^{b}$ & $88 \pm 18^{a}$ & $89 \pm 48^{a}$ & $49 \pm 9 a$ & $52 \pm 6^{a}$ & $50 \pm 26$ & $42 \pm 22^{b}$ \\
\hline $\begin{array}{l}50 \% \text { pectina } \\
\text { e celulose }\end{array}$ & $123 \pm 29 a$ & $115 \pm 19 b$ & $94 \pm 34$ a & $91 \pm 31$ a & $49 \pm 6^{a}$ & $53 \pm 4$ a & $54 \pm 27$ a & $43 \pm 22^{b}$ \\
\hline
\end{tabular}

*Valores expressos como média \pm desvio padrão. Letras diferentes na mesma coluna diferem estatisticamente $(p<0,05)$. 
observou-se elevação de $40,7 \%$ na concentração de CT dos animais do grupo controle ao passo que nos animais dos grupos experimentais e per feeding houve redução em relação a concentração inicial. Nos animais dos grupos que receberam o cubiu, a redução da concentração de CT foi de $15,2 \%, 18 \%$ e $21,6 \%$ para os grupos que receberam respectivamente dietas com $5 \%, 25 \%$ e $50 \%$ de farinha, e inversamente, os grupos que receberam tratamento com $5 \%, 25 \%$ e $50 \%$ de pectina e celulose obtiveram redução de $22,8 \%, 4,5 \%$ e $6,7 \%$. A concentração de HDL-c apresentou-se significativamente maior nos grupos testados em relação ao grupo controle $(p<0,05)$. Os grupos que receberam a $5 \%, 25 \%$ e $50 \%$ farinha de cubiu obtiveram melhores resultados em relação às concentrações de HDL-c, apresentando aumento de $36,6 \%, 18,9 \%$ e $16,3 \%$ respectivamente (Tabela $3)$. As concentrações de LDL-c foram reduzidas significativamente $(p<0,05)$ nos animais dos grupos que receberam os tratamentos com farinha de cubiu e com pectina e celulose. A dieta com $50 \%$ de farinha de cubiu foi responsável pela maior redução das concentrações de LDL-c, 56,8\% (Tabela 3).

Analisando a tabela 4 é possível verificar que todos os tratamentos testados reduziram o colesterol hepático em relação ao grupo controle. Os melhores resultados foram obtidos com as dietas contendo $25 \%$ e $50 \%$ de farinha de cubiu, onde a redução de colesterol hepático foi de 32,1\% e 31,7\%. Os animais que receberam tratamento com farinha de cubiu e com pectina e celulose apresentaram

TABELA 4. Colesterol fecal e hepático de ratos submetidos a dieta hipercolesterolêmica e tratados com farinha de cubiu..

\begin{tabular}{|c|c|c|}
\hline Grupos & $\begin{array}{l}\text { Colesterol fecal } \\
(\mathrm{mg} / \mathrm{dL})^{\star}\end{array}$ & $\begin{array}{l}\text { Colesterol hepático } \\
(\mathrm{mg} / \mathrm{dL})^{*}\end{array}$ \\
\hline Controle & $89,5 \pm 4,9$ & $240,91 \pm 4,2$ \\
\hline $\begin{array}{l}5 \% \text { farinha } \\
\text { de cubiu }\end{array}$ & $160,1 \pm 3,8$ & $167,28 \pm 17,3$ \\
\hline $\begin{array}{l}25 \% \text { farinha } \\
\text { de cubiu }\end{array}$ & $192,1 \pm 11,0$ & $163,57 \pm 12,7$ \\
\hline $\begin{array}{l}50 \% \text { farinha } \\
\text { de cubiu }\end{array}$ & $193,8 \pm 14,4$ & $164,33 \pm 14,1$ \\
\hline $\begin{array}{l}5 \% \text { pectina } \\
\text { e celulose }\end{array}$ & $150,4 \pm 9,1$ & $171,13 \pm 13,3$ \\
\hline $\begin{array}{l}25 \% \text { pectina } \\
\text { e celulose }\end{array}$ & $194,6 \pm 12,3$ & $193,21 \pm 15,1$ \\
\hline $\begin{array}{l}50 \% \text { pectina } \\
\text { e celulose }\end{array}$ & $196,9 \pm 12,6$ & $167,05 \pm 12,0$ \\
\hline
\end{tabular}

* Valores expressos como média \pm desvio padrão. excreção de colesterol fecal aumentada em relação ao grupo controle, sendo o maior valor encontrado nos animais dos grupos que receberam dieta com $25 \%$ e $50 \%$ pectina e celulose.

\section{DISCUSSÃO}

A análise química do cubiu demonstrou alto teor de umidade e baixa concentração de proteínas, resultados que corroboram os apresentados por Yuyama et al. (2007). Já o teor de lipídeos encontrado foi inferior aos encontrados por Yuyama et al. (2008) e Yuyama et al. (2005) e o de carboidratos, superior aos resultados encontrados por Pires et al. (2006). O valor de fibra alimentar encontrado está dentro da faixa observada na literatura (Yuyama et al., 2005; Yuyama et al., 2008). Desta forma o cubiu pode ser considerado um fruto altamente dietético, sendo uma opção para nortear a alimentação de indivíduos com sobrepeso e obesidade e também aqueles com restrição energética (Yuyama et al,. 2007).

Alguns estudos relatam um aumento na saciedade e na redução do apetite após o consumo de dietas ricas em fibras, no entanto os resultados obtidos no presente estudo não demonstraram esta associação, possivelmente pelo fato de que o conteúdo de fibras alimentares das dietas oferecidas não ultrapassaram as recomendações. El-Arab (2009) utilizou ratos wistar alimentados com dieta acrescida de colesterol $(0,25 \%)$ e vegetais folhosos como fontes de fibra alimentar (jew's mallow) para avaliar a evolução do perfil lipídico de ratos, e também não foi verificada diferença significativa no consumo das dietas e no ganho de massa corporal. Silva et al. (2003) não verificaram diferença no consumo e no ganho de peso de ratos ingerindo dietas com $5 \%, 10 \%$ e $15 \%$ de farelo de aveia, como fonte de fibra solúvel e farelo de trigo, fonte de fibra insolúvel. Também não foram observadas diferenças significativas entre o consumo de dietas e ganho de massa corporal no estudo de Eufrásio et al. (2009), utilizando ratos alimentados com dietas contendo diferentes tipos de fibras (pectina, goma guar e celulose).

Após a verificação da eficiência do modelo de indução utilizado, foi testado o possível efeito hipocolesterolêmico de diferentes tratamentos com farinha de cubiu, celulose e pectina, em diferentes doses, na lipemia dos ratos. Neste contexto, o perfil lipídico, o colesterol hepático e fecal dos animais foram investigados.

As concentrações plasmática de TG não apresentaram diferenças significativas entre os grupos. Resultados semelhantes foram obtidos em estudo realizado com fibra oriunda do feijão onde não foram observadas reduções significativas nas

Rev. Bras. PI. Med., Campinas, v.17, n.1, p.112-119, 2015. 
concentrações de TG nos grupos testados (Rosa et al., 1998). Luján et al. (2008) também não verificaram diferenças significativas nas concentrações de TG, em pesquisa realizada com ratos alimentados com diferentes variedades de feijão. Por outro lado, vários estudos registraram diminuição das concentrações de TG pela administração de diferentes fontes de fibras alimentares. O consumo de fibras solúveis promove o retardo do esvaziamento gástrico, levando a uma diminuição dos níveis de TG após a ingestão de refeições gordurosas. Elas podem também diminuir a absorção intestinal de triglicerídeos, provocando ligeiro aumento na gordura fecal contribuindo assim para a redução dos TG sanguíneo (Nishina \& Freedland, 1990). O fato dos resultados apresentados nesse estudo não demonstrarem tais efeitos, pode indicar que as doses experimentais testadas foram insuficientes para promover redução dos TG.

Todos os tratamentos apresentaram redução significativa de $C T$ e LDL-c $(p<0,05)$, sendo que o grupo que recebeu tratamento com $50 \%$ de farinha de cubiu apresentou os melhores resultados. Apesar da redução de CT obtida com os diferentes tratamentos, pode-se observar que em nenhum deles a concentração do CT alcançou os valores normais. Resultados semelhantes foram apresentados na pesquisa de Nicolle et al. (2004) utilizando o alface como fonte de fibras. Silva et al. (2003) observaram redução de $7 \%$ da concentração de CT em ratos que receberam, durante 63 dias, dietas com $15 \%$ de farelo de aveia. Em estudo, utilizando ratos alimentados com dietas acrescidas de banha de porco e diferentes doses de resíduo do abacaxizeiro, Piedade \& Canniati-Brazaca (2003) observaram, após 45 dias de tratamento, redução em torno de $21,5 \%$ na concentração de CT dos animais que receberam $25 \%$ de resíduo. A administração de dieta hipercolesterolêmica adicionada de $25 \%$ de maçã gala demonstrou redução de $20,7 \%$ da concentração de CT em ratos, após 30 dias de tratamento (Salgado et al., 2008). Comparandose os resultados aqui apresentados com os da literatura, é possível verificar que a redução da concentração de CT obtida com a administração de farinha de cubiu por 14 dias é semelhante, e às vezes superior às obtidas com administração de outros frutos por período de tratamento superiores, indicando que com a administração do cubiu, os resultados são obtidos mais rapidamente.

Diversas pesquisas realizadas com animais e também humanos tem demonstrado que as fibras solúveis agem favoravelmente à redução da concentração de colesterol sanguíneo. Alguns autores atribuem a ação das fibras solúveis na redução do CT e LDL-c à capacidade físico- química que elas tem de se ligar aos ácidos biliares carregando-os para as fezes, impedindo sua absorção pelo fígado, obrigando o fígado a sintetizar novos sais biliares a partir do colesterol sanguíneo. $A$ fibra solúvel pode também reduzir as concentrações de colesterol sanguíneo pela formação de uma estrutura viscosa que reduz a absorção de compostos como lipídeos e colesterol no intestino delgado (Nishina \& Freedland, 1990; Sembriesa et al., 2004; Shivasta \& Goyal, 2007; Garcia-Diez et al., 1996). A fermentação das fibras pelas colônias de bactérias que existem no intestino grosso acaba por produzir ácidos graxos de cadeia curta podendo também influenciar a lipemia. Os ácidos graxos de cadeia curta influenciam a absorção de lipídeos e o metabolismo das lipoproteínas no fígado, promovendo consequentemente à utilização de colesterol sanguíneo (Marcil et al, 2002).

Em todos os grupos testados, o aumento da concentração de HDL-c foi significativo $(p<0,05)$, sendo o melhor resultado obtido no grupo que recebeu dieta com $50 \%$ de farinha de cubiu, onde o HDL-c foi $81,9 \%$ maior do que no grupo controle, após os 14 dias de tratamento. Analisando os resultados, é possível se afirmar que os tratamentos foram eficazes na redução do risco de doenças cardiovasculares, uma vez que em estudos epidemiológicos realizados, a alta concentração de HDL-c sanguíneo é tida como efeito protetor contra as DCV (Magalhães et al., 2002).

Analisando a Tabela 4 é possível verificar que todos os tratamentos testados reduziram o colesterol hepático em relação ao grupo controle. Os melhores resultados foram obtidos com as dietas contendo $25 \%$ e $50 \%$ de farinha de cubiu, onde a redução de colesterol hepático foi de 32,1\% e 31,7\%. A diminuição das concentrações de colesterol hepático observadas podem ser devido a ingestão das fibras alimentares as quais reduzem a absorção de sais biliares pelo fígado promovendo depleção do colesterol hepático, como substrato da síntese de novos ácidos biliares que foram perdidos nas fezes (Camire \& Dougherty, 2003).

O efeito da fibra solúvel na lipemia dos animais também é verificado após análise do colesterol hepático e fecal, onde os grupos que receberam os tratamentos apresentaram concentração de colesterol hepático inferior ao grupo controle e concentração de colesterol fecal superior. Fato que pode ser explicado pela hipótese de que as fibras solúveis podem se ligar aos ácidos biliares, aumentando sua excreção nas fezes, diminuindo a reabsorção, obrigando o fígado a produzir novos ácidos biliares a partir do colesterol sanguíneo (Sembriesa et al., 2004; Shivasta \& Goyal, 2007; Garcia-Diez et al.; 1996 e Marcil et al., 2002). 


\section{CONCLUSÃO}

A administração da farinha de cubiu reduziu as concentrações de colesterol total, LDL-c e colesterol hepático, e aumentou a excreção de colesterol pelas fezes e o HDL-c em ratos hipercolesterolêmicos. Os resultados observados confirmam o uso popular do fruto como hipocolesterolemiante e podem servir como base para futuros estudos visando o aproveitamento biotecnológico da espécie estudada.

\section{AGRADECIMENTOS}

Os autores agradecem o financiamento recebido pelo Ministério da Ciência e Tecnologia (MCT) e ao Conselho Nacional de Desenvolvimento Tecnológico e Científico (CNPq) através de recursos do Edital CT-Amazônia. Também ao Instituto Nacional de Pesquisas da Amazônia (INPA) e ao estatístico Edson da Fonseca de Lira da Fundação de Hematologia e Hematoterapia do Estado do Amazonas. Agradecimento in memorian a Profa. Dra, Lucia K.O. Yuyama, a qual foi orientadora e idealizadora do trabalho.

\section{REFERÊNCIAS}

ASSOCIATION OF OFFICIAL ANALYTICAL CHEMISTS - AOAC. Official Methods of analysis. 16 ed. 1995.

ASP, N.G. et al. Rapid enzymatic assay in insoluble dietary fiber. Journal of Agricultural and Food Chemistry. v.31, p.43-53, 1983.

BHATNAGAR, D. Lipid-lowering drugs in management of hyperlipidemia. Pharmacology \& Therapeutics, v.79, p.205-230, 1998.

BRASIL. Lei 11.794, de 8 de outubro de 2008. Regulamenta o inciso VII do § 10 do art. 225 da Constituição Federal, estabelecendo procedimentos para o uso científico de animais; revoga a Lei no 6.638, de 8 de maio de 1979; e dá outras providências. In. Diário Oficial da União, Brasília, n.196, p.1-2, 9 de outubro de 2008.

CAMIRE, M. E.; DOUGHERTY, M. P. Raisin dietary fiber composition and in vitro bile acid binding. Journal of Agricultural and Food Chemistry, v.51, n.3, p.834837, 2003.

EI-ARAB, A.M.E. A diet rich in leafy vegetable fiber improves cholesterol metabolism in high-cholesterol fed rats. Pakistan Journal of Biological Sciences, v.12, n.10, p.1299-1306, 2009.

EUFRÁSIO, M.R. et al. Efeito de diferentes tipos de fibras sobre frações lipídicas do sangue e fígado de ratos wistar. Ciência e Agrotecnologia, v.33,n.6, p.16081614, 2009.

FUNG, T.T. et al. Dietary patterns and risk of coronary heart disease in women. Archives of Internal Medicine, v.161, n15, p.1857-1862, 2001.

FRIEDEWALD, W.T.; LEVY, R.I.; FREDRICKSON, D.S. Estimation of the concentration of low-density lipoprotein cholesterolin plasma, without use of the preparative ultracentrifuge. Clinical Chemistry, v.18, n.6, p. 499-
502, 1972.

GARCIA-DIEZ, F. et al. Pectin feeding influences fecal bile acid excretion, hepatic bile acid and cholesterol synthesis and serum cholesterol in rats. Journal of Nutrition, v.126, p.1766-1771, 1996.

HAUG, A.; HOSTMARK, A. T. Lipoprotein lipases, lipoproteins and tissue lipids in rats fed fish oil or coconut oil. Journal of Nutrition, v.117, n.6, p.1011-1017, 1987.

HU, F.B. et al. Prospective study of major dietary patterns and risk of coronary heart disease in men. The American Journal of Clinical Nutrition, v.72, p.912-921, 2000.

LUJÁN, D.L.B. et al. Variedades de feijão e seus efeitos na qualidade protéica, na glicemia e nos lipídeos sanguíneos em ratos. Ciência e Tecnologia de Alimentos., v.28 (sulp.), p.142-149, 2008.

MAGALHÃES, C. C; CHAGAS, A. C. P.; LUZ, P. L. Importância do HDL-colesterol como preditor de risco para eventos cardiovasculares. Sociedade Brasileira de Cardiologia, v.12, n.4, p.560-568, 2002.

MARCIL, V. et al. Modulation of lipid synthesis, apolipoprotein biogenesis, and lipoprotein assembly by butyrate. American Journal of Physiology, v.283, pG340-G346, 2002.

MOUNDRAS, C. et al. Fecal losses of sterols and bile acids induced by feeding rats guar gum are due to greater pool size and liver bile acid secretion. Journal of Nutrition, v.127, n.6, p.1068-1076, 1997.

NICOLLE, C. et al. Health effect of vegetable-based diet: lettuce consumption improves cholesterol metabolism and antioxidant status in the rat. Clinical Nutrition, v.23, n.4, p.605-614, 2004.

NISHINA, P.M.; FREEDLAND, R.A. The effects of dietary fiber feeding on cholesterol metabolism in rats. Journal of Nutrition, v.120, n.7, p.800-805, 1990.

PAHLEN, A.V.D. Cubiu [Solanum topiro (Humb. \& Bonpl.)], uma fruteira da Amazônia. Acta Amazônica, v.7, n.3, p.301-7, 1977.

PIEDADE, J.; CANNIATTI-BRAZACA, S. G. Comparação entre o efeito do resíduo do abacaxizeiro (caules e folhas) e da pectina cítrica de alta metoxilação no nível de colesterol sanguíneo em ratos. Ciência e Tecnologia de Alimentos, v. 23, n. 2, p. 149-156, 2003.

PIRES, A.M.B. et al. Caracterização e processamento de cubiu (Solanum sessiliflorum). Ceres, v.53, n.307, p.309-316, 2006.

REEVES, P.G.; NIELSEN, F.H.; FAHEY JR, G.C. AIN-93 Purified diets for laboratory rodents: final report of the American Institute of Nutrition ad hoc writing committee on the formulation of the AIN-76A rodent diet. Journal of Nutrition, v.123, p.1939-51, 1993.

ROSA, C.O.B. et al. Efeito dos feijões (Phaseolus vulgaris, L.) preto, carioquinha e vermelho na redução do colesterol sanguíneo de ratos hipercolesterolêmicos. Archivos Latinoamericanos de Nutrición, v.48, n.4, p.299-310, 1998.

SALGADO, J.M.; CURTI, F.; MANSI, D.N. Effect of gala apples (Malus domestica Borkh) on lipidemia of hyperlipidemic rats. Ciência e Tecnologia de Alimentos, v.28, n.2, p.477-484, 2008.

SEMBRIESA, S. et al. Dietary fiber-rich colloids from apple pomace extraction juices do not affect food intake and blood serum lipid levels, but enhance fecal excretion of steroids in rats. The Journal of Nutrition 
Biochemistry, v.15, n.5, p.296-302, 2004.

SHRIVASTVA, S.; GOYAL G. K. Therapeutic benefits of pro and prebiotics: a reveiw. Indian Food Industry, v.26, n.2, p.41-49, 2007.

SILVA FILHO, D.F. Cocona (Solanum sessiliflorum Dunal): cultivo y utilización. Caracas, Venezuela: Secretaria Pro-Tampore. Tratado de Cooperacion Amazonica, 1998. 105p.

SILVA FILHO, D.F. et al. Seleção de caracteres correlacionados em cubiu (Solanum sessiliflorum Dunal) empregando a análise de trilha. Acta Amazônica, v.27, n.4, p.229-240, 1997.

SILVA, M.A.M. et al. Efeito das fibras dos farelos de trigo e aveia sobre o perfil lipídico no sangue de ratos (Rattus novergicus) wistar. Ciência e Agrotecnologia, v.27,n.6, p.1321-1329, 2003.

TOSHIMA, S. et al. Circulating oxidized low density lipoprotein levels: A biochemical risk marker for coronary heart disease. Arteriosclerosis, Thrombosis and Vascular Biology, v.20, n.10, p.2243-2247, 2000.

YUYAMA, L.K.O. et al. Estudo da influência do cubiu (Solanum sessiliflorum Dunal)sobre a concentração sérica de glicose. Revista Instituto Adolfo Lutz, v.64, n.2, p.232-6, 2005.

YUYAMA, L.K.O. et al. Quantificação de macro e micro nutrientes em algumas etnovariedades de cubiu (Solanum sessiliflorum Dunal). Acta Amazônica, v.37, n.3, p. 425-30, 2007.

YUYAMA, L.K.O. et al. Desenvolvimento e aceitabilidade de geléia de cubiu (Solanum sessiliflorum Dunal). Ciência e Tecnologia de Alimentos, v.28, n.4, p.929934, 2008.

WARD, S. et al. A systematic review and economic evaluation of stains for the prevention of coronary events. International Journal of Technology Assessment in Health Care, v.11, n.14, p.1-160, 2007. 